\title{
Wrinkle-Free Single-Crystal Graphene Wafer Grown on Strain-Engineered Substrates
}

Bing Deng, ${ }^{\dagger}$ Z Zhenqian Pang, ${ }^{\ddagger}$ Shulin Chen, ${ }^{\S, \|}$ Xin Li, ${ }^{\perp, \#}$ Caixia Meng, ${ }^{\text {II }}$ Jiayu Li, $\square, \triangle$ Mengxi Liu, ${ }^{\perp}$ Juanxia Wu, ${ }^{\dagger}$ Yue Qi ${ }^{\dagger, \triangle}$ Wenhui Dang, ${ }^{\dagger}$ Hao Yang, ${ }^{\dagger, \triangle}$ Yanfeng Zhang, ${ }^{\dagger \odot}$ Jin Zhang, ${ }^{\dagger \oplus}$ Ning Kang, Hongqi Xu, ${ }^{\square \odot}$ Qiang Fu, ${ }^{\text {II }}$ Xiaohui Qiu, ${ }^{\perp}$ Peng Gao, ${ }^{\S}, \nabla \odot$ Yujie Wei, ${ }^{*},{ }^{\ddagger}$ Zhongfan Liu, ${ }^{*}, \dagger, \Omega_{\odot}$ and Hailin Peng $*,+, \infty_{0}$

${ }^{\dagger}$ Center for Nanochemistry (CNC), Beijing Science and Engineering Center for Nanocarbons, Beijing National Laboratory for Molecular Sciences (BNLMS), College of Chemistry and Molecular Engineering, Peking University, Beijing 100871, China

${ }^{\ddagger}$ LNM, Institute of Mechanics, Chinese Academy of Sciences, Beijing 100190, China

${ }^{\S}$ Electron Microscopy Laboratory, International Center for Quantum Materials, School of Physics, Peking University, Beijing 100871, China

"State Key Laboratory of Advanced Welding and Joining, Harbin Institute of Technology, Harbin 150001, China

${ }^{\perp}$ CAS Key Laboratory of Standardization and Measurement for Nanotechnology, CAS Center for Excellence in Nanoscience,

National Center for Nanoscience and Technology, Beijing 100190, China

${ }^{\#}$ University of Chinese Academy of Sciences, Beijing 100049, China

${ }^{\text {II }}$ State Key Laboratory of Catalysis, Collaborative Innovation Center of Chemistry for Energy Materials (iChEM), Dalian Institute of Chemical Physics, Chinese Academy of Sciences, Dalian 116023, China

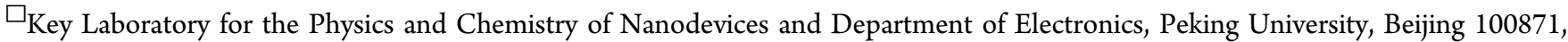
China

$\triangle_{\text {Academy for Advanced Interdisciplinary Studies, Peking University, Beijing 100871, China }}$

$\nabla_{\text {Collaborative Innovation Center of Quantum Matter, Beijing 100871, China }}$

${ }^{\circ}$ Beijing Graphene Institute (BGI), Beijing 100094, China

S Supporting Information

ABSTRACT: Wrinkles are ubiquitous for graphene films grown on various substrates by chemical vapor deposition at high temperature due to the strain induced by thermal mismatch between the graphene and substrates, which greatly degrades the extraordinary properties of graphene. Here we show that the wrinkle formation of graphene grown on $\mathrm{Cu}$ substrates is strongly dependent on the crystallographic orientations. Wrinkle-free single-crystal graphene was grown on a wafer-scale twin-boundary-free single-crystal $\mathrm{Cu}(111)$ thin film fabricated on sapphire substrate through strain engineering. The wrinkle-free feature of graphene originated from the relatively small thermal expansion of the $\mathrm{Cu}(111)$ thin film substrate and the relatively strong interfacial coupling between $\mathrm{Cu}(111)$ and graphene, based on the strain analyses as well as molecular dynamics simulations. Moreover, we demonstrated the transfer of an ultraflat graphene film onto target substrates from the reusable single-crystal $\mathrm{Cu}(111)$ /sapphire growth substrate. The wrinkle-free graphene shows enhanced electrical mobility compared to graphene with wrinkles.

KEYWORDS: graphene wrinkle, ultraflat, strain engineering, single crystal, thermal mismatch
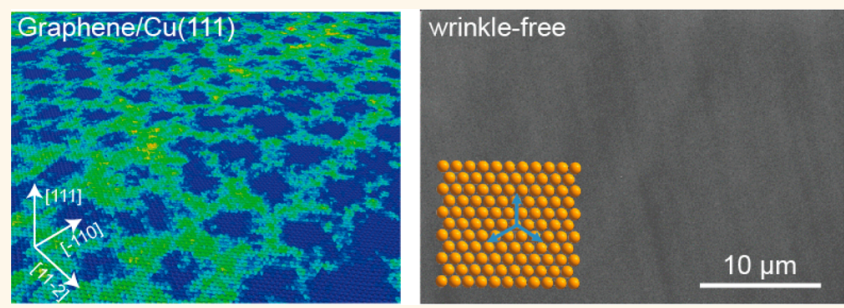

hemical vapor deposition (CVD) growth of high-quality graphene films on various metal substrates, including $\mathrm{Cu},{ }^{1,2} \mathrm{Ni}^{3,4}$ and $\mathrm{Pt},{ }^{5}$ has been extensively investigated to fulfill various requirements for device applications. ${ }^{6,7}$ Even though tremendous efforts have been taken to eliminate grain boundaries by growing large single-crystal graphene, ${ }^{5,8,9}$ graphene wrinkles ${ }^{3,10-12}$ the other ubiquitous linear defect sites have far less been addressed. ${ }^{13,14}$ Graphene wrinkles may cause anisotropic electrical mobility, ${ }^{12}$ local charge accumulation, ${ }^{15}$ anticorrosion degradation, ${ }^{16}$ and mechanical strength/thermal conductivity

Received: August 31, 2017

Accepted: November 30, 2017

Published: November 30, 2017 

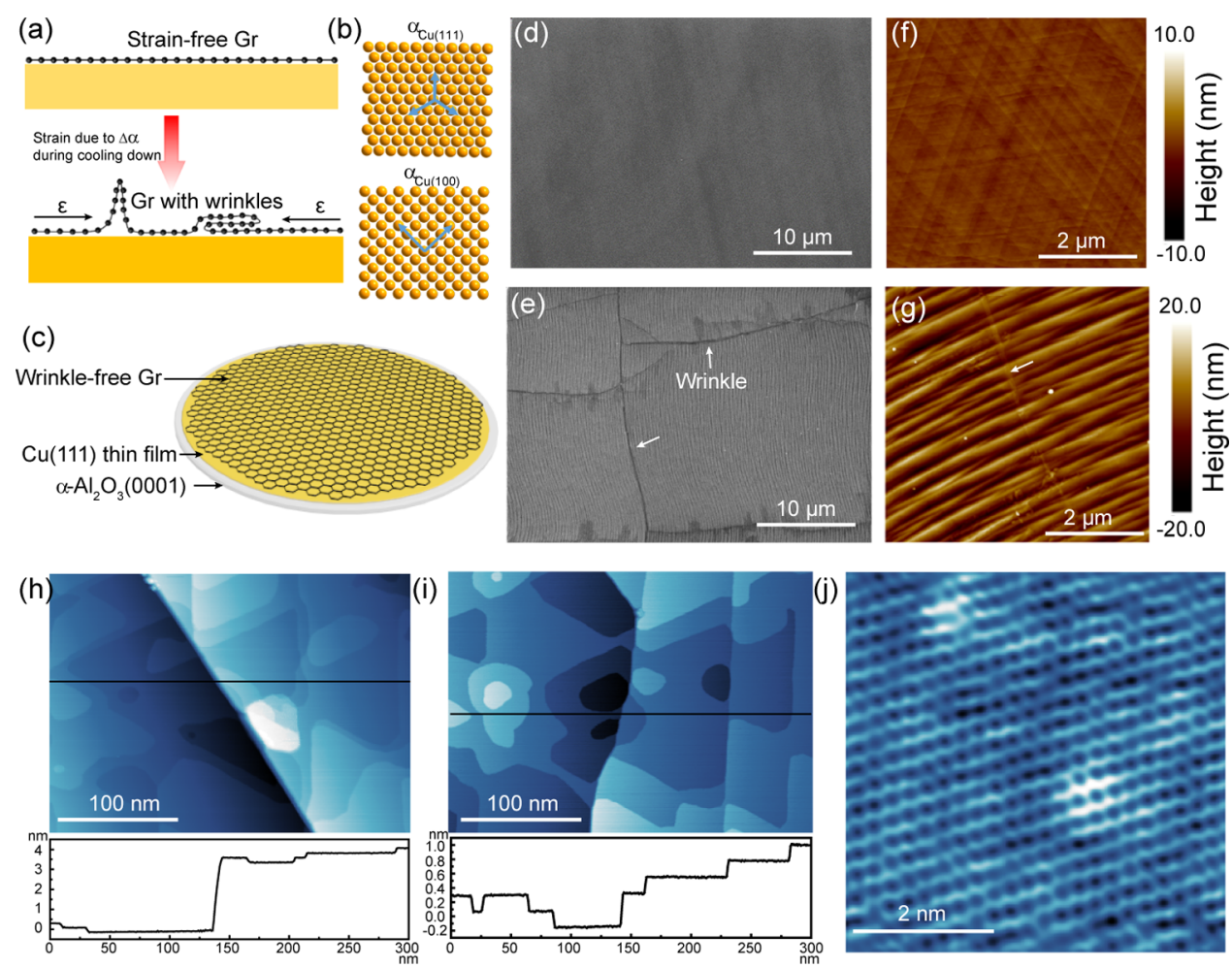

Figure 1. Wrinkle-free graphene growth on $\mathrm{Cu}(111)$ thin film. (a) Schematic of the wrinkle formation process of graphene (Gr) grown on a substrate. The black arrow shows the compressive strain of graphene induced by the thermal mismatch during cooling. (b) Crystal face model of $\mathrm{Cu}(111)$ and $\mathrm{Cu}(100)$. (c) Schematic of the wrinkle-free graphene grown on $\mathrm{Cu}(111)$ thin film epitaxial on sapphire. (d, e) SEM images of graphene grown on $\mathrm{Cu}(111)$ thin film and $\mathrm{Cu}(100)$ foil, respectively. (f, g) $\mathrm{AFM}$ images of graphene grown on $\mathrm{Cu}(111)$ thin film and $\mathrm{Cu}(100)$ foil, respectively. (h, i) STM images of graphene on a $\mathrm{Cu}(111)$ surface with large $\mathrm{Cu}$ step bunch and atomic $\mathrm{Cu}$ steps, respectively. The line profiles marked by black lines are shown below. (j) Atomic-resolution STM image of graphene on a Cu(111) surface.

reduction. ${ }^{15,17}$ Especially the inhomogeneity caused by graphene wrinkles is of serious concern for industrial applications of graphene films, ${ }^{18}$ where high reproducibility and reliability are required during top-down fabrication and device integration. Until now, only very limited growth methods were proposed to address the grain boundaries and wrinkles simultaneously. For example, Jae-Hyun Lee et al. reported the growth of wrinkle-free and single-crystal graphene on hydrogen-terminated germanium. ${ }^{19}$ The wrinkle-free nature of graphene on germanium was inferred from the extremely weak adhesion and relatively small difference in thermal expansion coefficient (CTE) between the materials.

Graphene wrinkles can form during both the growth and transfer process. Intrinsic graphene wrinkles formed during the growth are impossible to release by transfer, although graphene ripples induced by corrugated substrates can be released by reformative transfer methods. ${ }^{20,21}$ As schematically illustrated in Figure 1a, the wrinkle formation of graphene grown on $\mathrm{Cu}$ mainly originated from the compressive strain relaxation. In principle, during cooling in the CVD process, the mismatch of CTE between graphene $\left(\alpha_{\mathrm{Gr}}\right)^{22,23}$ and $\mathrm{Cu}$ substrate $\left(\alpha_{\mathrm{Sub}}\right)$ will induce strong compressive strain $\left(\varepsilon \approx \Delta T\left(\alpha_{\mathrm{Gr}}-\alpha_{\mathrm{Cu}}\right)\right.$ for a temperature drop $\Delta T)$ in the graphene film. Once the strain energy is large enough to overcome the activation energy for wrinkle formation, the graphene layer buckles to form wrinkles ${ }^{24}$ and relaxes its in-plane compression at the expenses of interfacial energy due to delamination and bending energy in wrinkles. The activation energy relies on how strong the graphene is bonded to the substrate. $^{24,25}$ To date, the growth of wrinkle-free graphene on the $\mathrm{Cu}$ substrate is still particularly challenging for two reasons.
First, the large thermal expansion mismatch between $\mathrm{Cu}\left(\alpha_{\mathrm{Cu}}=\right.$ $\left.16.6 \times 10^{-6} / \mathrm{K}\right)$ and graphene $\left(\alpha_{\mathrm{Gr}}=-7 \times 10^{-6} / \mathrm{K}\right)^{22,23}$ induces strain in graphene as large as $\sim 2 \%$ when cooling, supposing a growth temperature of $\sim 1000{ }^{\circ} \mathrm{C}$. Note that CTE is temperature-dependent. Second, the relatively weak graphene- $\mathrm{Cu}$ interaction $^{26}$ allows for in-plane slipping and delamination, and the latter leads to out-of-plane buckling of graphene under the strain. Therefore, reducing the thermal expansion mismatch and enhancing the graphene- $\mathrm{Cu}$ interaction might satisfy those key requirements for the growth of wrinkle-free graphene on $\mathrm{Cu}$ substrate.

The thermal dynamics of $\mathrm{Cu}$ crystal facets are highly related to their crystallographic orientations. ${ }^{27-30}$ Among them, $\mathrm{Cu}(111)$ is the most compact and lowest energy surface with the smallest thermal expansion along three equivalent lattice directions (Figure $1 \mathrm{~b})$, whereas $\mathrm{Cu}(100)$, for instance, has larger thermal expansion. ${ }^{30}$ Moreover, the interaction of graphene with $\mathrm{Cu}(111)$ is larger than that of $\mathrm{Cu}(100)$ and $\mathrm{Cu}(110)$ based on both experimental measurements and theoretical calculations. ${ }^{31,32}$ Until now, systematic investigations on the relationship between graphene wrinkle formation and $\mathrm{Cu}$ crystallographic orientations, as well as large-area growth of wrinkle-free graphene film, have not been reported to the best of our knowledge. Herein we show that graphene is wrinkle-free grown on $\mathrm{Cu}(111)$ thin film, whereas it is wrinkled on other surfaces such as $\mathrm{Cu}(100)$ and $\mathrm{Cu}(110)$. Through the strain engineering of the substrate, the wrinkle-free single-crystal graphene was repeatedly grown on a reusable 4 in. epitaxial single-crystal $\mathrm{Cu}-(111)$ thin film fabricated on an $\alpha-\mathrm{Al}_{2} \mathrm{O}_{3}(0001)$ sapphire substrate. Finally, we demonstrate that 

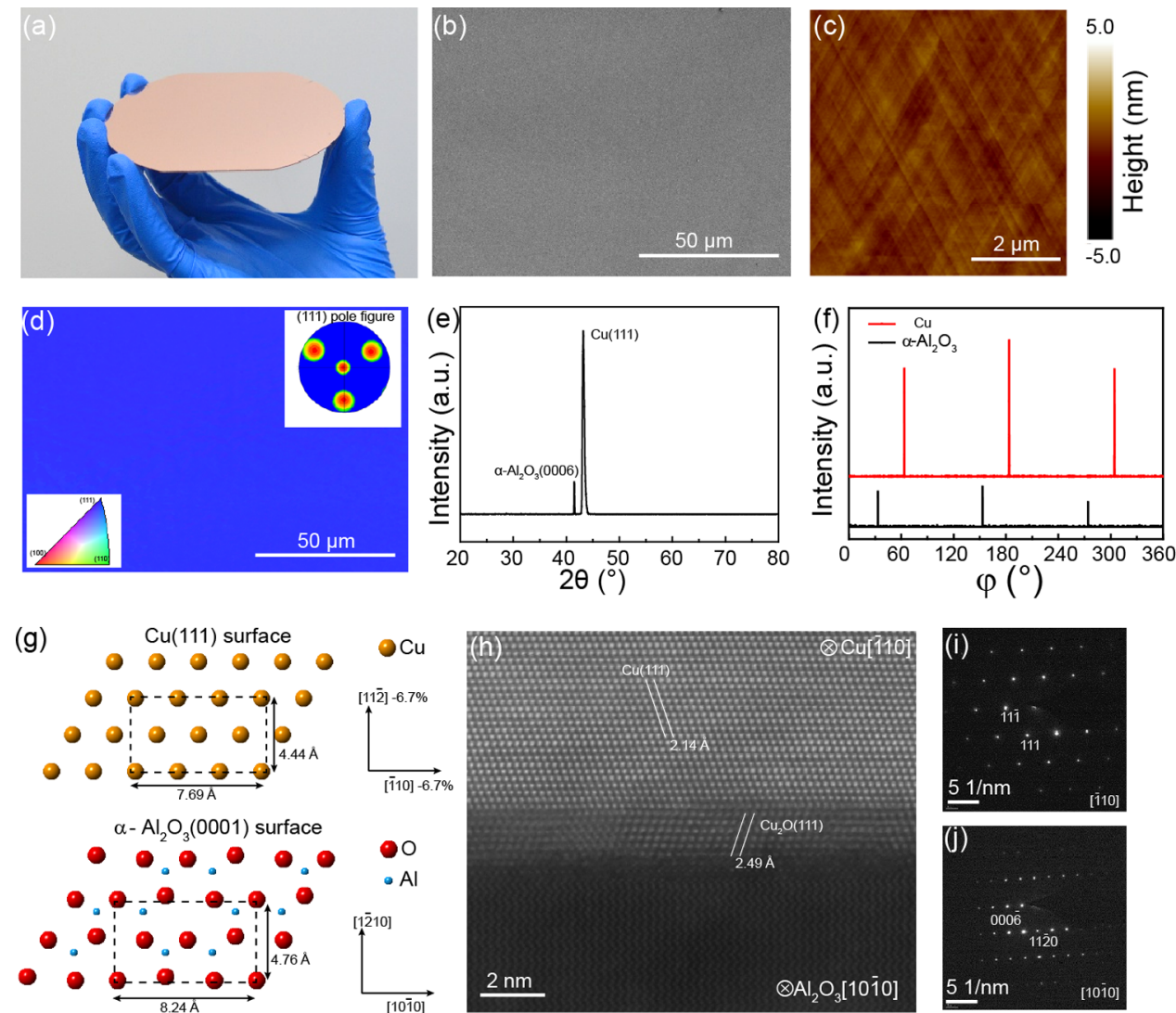

Figure 2. Wafer-scale single-crystal $\mathrm{Cu}(111)$ thin film fabrication on sapphire. (a) Photograph of a 4 in. single-crystal $\mathrm{Cu}(111)$ thin film on $\alpha-\mathrm{Al}_{2} \mathrm{O}_{3}$. (b) SEM image and (c) AFM morphology image of $\mathrm{Cu}(111)$ thin film. (d) EBSD map of Cu thin film on $\alpha$ - $\mathrm{Al}_{2} \mathrm{O}_{3}$. Inset shows the pole figure of $\mathrm{Cu}(111)$. (e) XRD pattern of $\mathrm{Cu}$ /sapphire, showing the well-defined $\mathrm{Cu}(111)$ out-of-plane orientation. (f) HRXRD azimuthal off-axis $\varphi$ scan of $\mathrm{Cu}(111)$ using $\mathrm{Cu}(200)$ as Bragg position, and $\alpha-\mathrm{Al}_{2} \mathrm{O}_{3}(0001)$ using $\alpha-\mathrm{Al}_{2} \mathrm{O}_{3}(02 \overline{2} 4)$ as Bragg position. (g) Schematic of the orientation relationship between $\mathrm{Cu}(111)$ and oxygen-terminated $\alpha-\mathrm{Al}_{2} \mathrm{O}_{3}(0001)$. (h) STEM image of the interface regions of $\mathrm{Cu} / \alpha-\mathrm{Al}_{2} \mathrm{O}_{3}$ along the zone axis of $[\overline{1} 10]_{\mathrm{Cu}}$ and $[10 \overline{10}]_{\alpha \text {-Al2O3 }}$ (i) SAED obtained from the $\mathrm{Cu}$ film. (j) SAED obtained from the $\alpha-\mathrm{Al}_{2} \mathrm{O}_{3}$ substrate.

the wrinkle-free single-crystal graphene shows much improved electronic properties.

\section{RESULTS AND DISCUSSION}

The growth and transfer process of wrinkle-free graphene are schematically illustrated in Figure 1c and Supporting Information Figure S1. The morphology of as-grown graphene was carefully investigated by scanning electron microscopy (SEM), atomic force microscopy (AFM), and scanning tunneling microscopy (STM). As shown in a typical SEM image (Figure 1d), large-area graphene film grown on $\mathrm{Cu}(111)$ thin film shows very uniform contrast without any wrinkles (more data are shown in Supporting Information Figure S2). Note that the graphene growth was under atmospheric pressure to reduce the sublimation of $\mathrm{Cu}$ and maintain the substrate flatness during growth (Supporting Information Figure S3). ${ }^{33}$ Graphene films grown on $\mathrm{Cu}$ foil under similar conditions were also obtained. In contrast, large amounts of graphene wrinkles commonly formed on (100)-orientated $\mathrm{Cu}$ foil are visible as dark contrast in the SEM image because these regions reflect fewer secondary electrons (Figure 1e, Supporting Information Figure S4).

AFM images further revealed the local flatness of graphene films on a $\mathrm{Cu}(111)$ thin film substrate, in which no wrinkles were detected on the whole surface (Figure 1f, Supporting Information Figure S5). The root-mean-square (RMS) roughness of graphene/ $\mathrm{Cu}(111)$ is $\sim 0.408 \mathrm{~nm}$ in the AFM image region of $25 \mu \mathrm{m}^{2}$. In contrast, graphene wrinkles on $\mathrm{Cu}(100)$ foil can be visualized easily in a typical AFM image (Figure $1 \mathrm{~g}$ ). The apparent wrinkle at the height of $\sim 1.6 \mathrm{~nm}$ indicates the folded structure (Supporting Information Figure S6). Apart from the formation of graphene wrinkles, the $\mathrm{Cu}(100)$ surface underwent severe surface reconstruction to form dense step bunches at a height of $\sim 10 \mathrm{~nm}$ for strain relaxation, ${ }^{11}$ resulting in the RMS roughness of graphene $/ \mathrm{Cu}(100)$ of up to $3.92 \mathrm{~nm}$, much larger than that of graphene $/ \mathrm{Cu}(111)$. Furthermore, STM imaging with an ultrahigh vertical resolution was conducted to characterize the as-grown graphene film (Figure $1 \mathrm{~h}-\mathrm{j}$ ). ${ }^{34,35}$ The typical atomic-resolution STM image of graphene reveals the honeycomb-like lattices (Figure 1j). Remarkably, no wrinkle was observed in graphene films grown on both the terraces and step edges of the $\mathrm{Cu}(111)$ surface with different step heights from $\sim 3 \mathrm{~nm}$ (Figure $1 \mathrm{~h}$ ) to $\sim 0.3 \mathrm{~nm}$ (Figure 1i). To sum up, we can undoubtedly conclude that graphene film grown on single-crystal $\mathrm{Cu}(111)$ thin film on sapphire is ultraflat and wrinkle-free. Note that the impurity-free and ultraflat feature of $\mathrm{Cu}(111)$ thin film might be crucial for the wrinkle-free graphene growth.

In addition to the wrinkle-free feature of graphene film, the use of the single-crystal $\mathrm{Cu}(111)$ substrate enables epitaxial growth of aligned graphene domains (Supporting Information Figures S7-9), which subsequently seamlessly stitch together to form a single-crystal monolayer graphene at the wafer scale (Supporting Information Figures S10-12). ${ }^{36,37}$

To realize wafer-scale growth of wrinkle-free graphene, the prerequisite challenge lies in the fabrication of a wafer-size single-crystal 

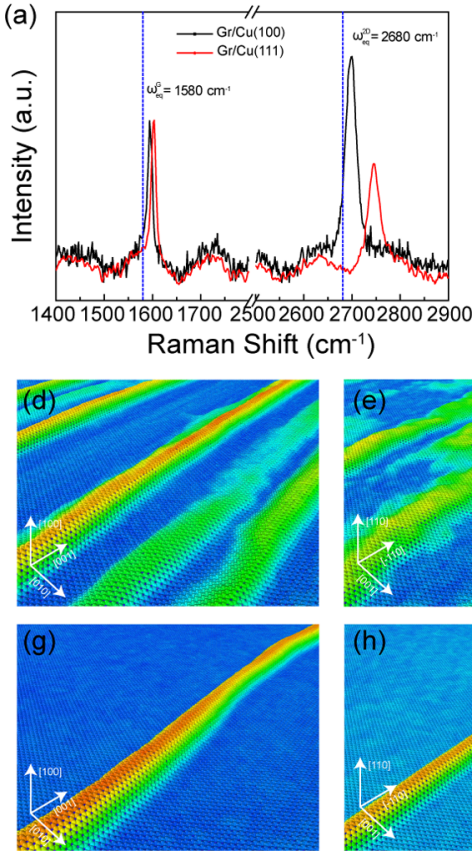
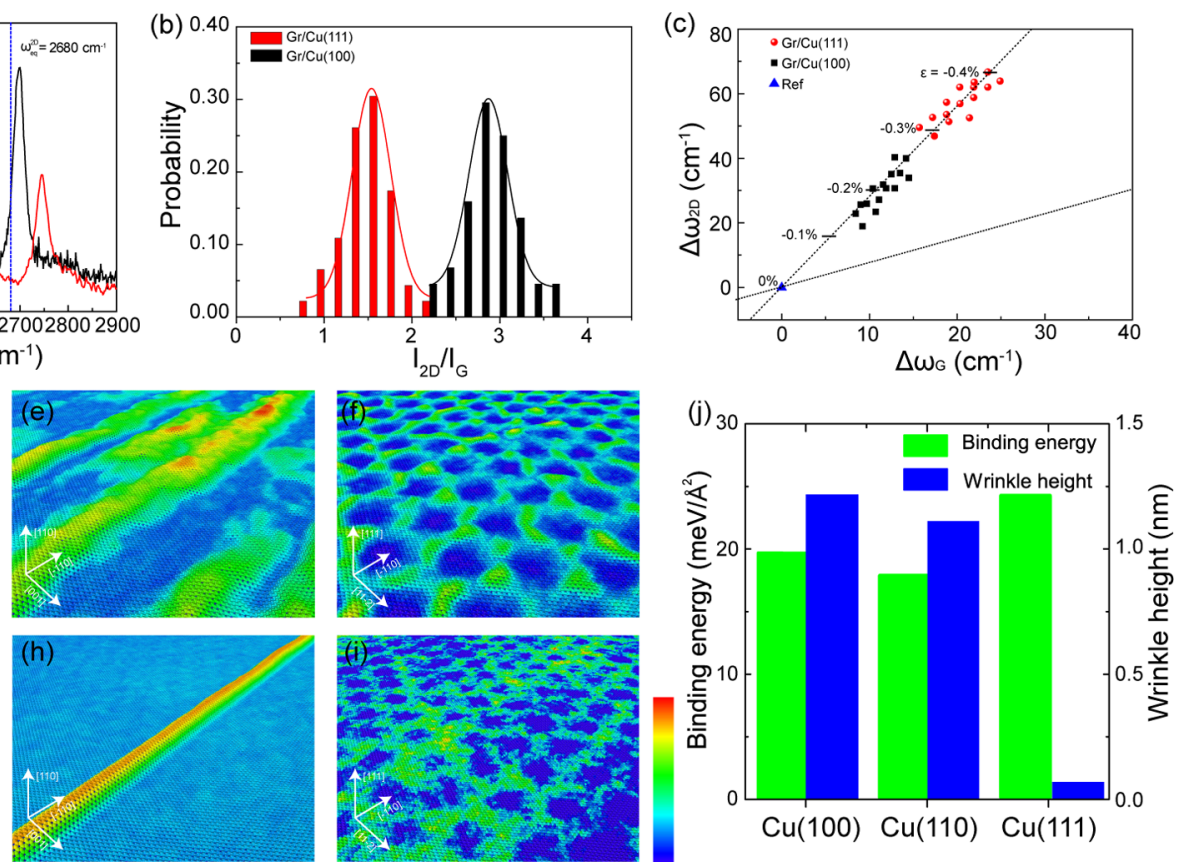

Figure 3. Strain and doping analysis and the molecular dynamic stimulation of wrinkle formation on Cu crystallographic planes. (a) Representative Raman spectra of graphene grown on $\mathrm{Cu}(111)$ thin film and $\mathrm{Cu}(100)$ foil. The fluorescence background signals of $\mathrm{Cu}$ have been deducted. The blue lines mark the $G$ band and $2 D$ band positions of strain-free intrinsic graphene. (b) Probability distribution of the intensity ratio of the 2D peak and $\mathrm{G}$ peak. (c) $\Delta \omega_{2 \mathrm{D}}-\Delta \omega_{\mathrm{G}}$ correlation of the graphene on $\mathrm{Cu}(111)$ thin film and $\mathrm{Cu}(100)$ foil. The steep dashed line with a slope of 2.7 indicates a charge neutral line assuming $\partial \omega_{2 D} / \partial \varepsilon \approx-57.3$ and $\partial \omega_{G} / \partial \varepsilon \approx-160.3$ (ref 53); the dashed line with a slope of 0.75 was associated with hole doping (ref 52). (d-i) Morphology of graphene on various $\mathrm{Cu}$ crystallographic planes under the compressive thermal strains from the depositing temperature of $1300 \mathrm{~K}$ to room temperature $(300 \mathrm{~K})$. ( $\mathrm{d}-\mathrm{f})$ Morphology of graphene at $300 \mathrm{~K}$ after relaxation on $\mathrm{Cu}(100)$, $\mathrm{Cu}(110)$, and $\mathrm{Cu}(111)$ planes, respectively. ( $\mathrm{g}-\mathrm{i})$ Morphology of graphene after a sufficiently long period on $\mathrm{Cu}(100), \mathrm{Cu}(110)$, and $\mathrm{Cu}(111)$, respectively. Color reflects the height of wrinkles. (j) Dependence of binding energy and wrinkle height on Cu crystallographic planes.

$\mathrm{Cu}(111)$ substrate. Several groups have reported the fabrication of epitaxial $\mathrm{Cu}(111)$ thin film on sapphire, yet the in-plane twin boundaries are always observed since the epitaxy between a (111) cubic film and a hexagonal substrate is equivalent for a $60^{\circ}$ in-plane orientation. ${ }^{38-40}$ The twin boundaries can induce deep thermal grooves, which degrade the flatness of the $\mathrm{Cu}$ thin film and hinder the epitaxy relationship between $\mathrm{Cu}(111)$ and graphene. Very recently, an appropriate combination of the use of a fine single-crystal $\mathrm{Cu}(111)$ target and precise temperature control of the sapphire substrate during magneton sputtering was proposed to fabricate a 2 in. single-crystal $\mathrm{Cu}(111)$ thin film. ${ }^{41}$

In contrast with previous reports, we herein use a low-cost polycrystalline $\mathrm{Cu}$ target to deposit a single-crystal $\mathrm{Cu}(111)$ thin film without in-plane twin structures on an oxygen anneal ing pretreated sapphire substrate. Briefly, a 4-in.-sized c-plane $\alpha-\mathrm{Al}_{2} \mathrm{O}_{3}(0001)$ substrate was cleaned and annealed at $1000{ }^{\circ} \mathrm{C}$ in a pure oxygen atmosphere for $12 \mathrm{~h}$, followed by $\mathrm{Cu}$ magnetron sputtering with a commercial coarse $\mathrm{Cu}$ target immediately. Then, the as-deposited $\mathrm{Cu} /$ sapphire was annealed at $1000{ }^{\circ} \mathrm{C}$ in $\mathrm{Ar} / \mathrm{H}_{2}$ atmosphere for recrystallization.

As-deposited $\mathrm{Cu}$ on sapphire is (111)-oriented yet very rough with poor crystallinity (Supporting Information Figure S13). The postannealing process of $\mathrm{Cu}$ /sapphire results in the giant grain growth, ${ }^{42}$ and eventually wafer-scale single-crystal $\mathrm{Cu}(111)$ thin film can grow on the $\alpha-\mathrm{Al}_{2} \mathrm{O}_{3}(0001)$ substrate (Figure 2a). The largearea optical microscopy (OM) images (Supporting Information Figure S14) and SEM images (Figure 2b, Supporting Information Figure $\mathrm{S} 15)$ verify that the $\mathrm{Cu}(111)$ thin film almost does not have any obvious grain boundaries. More importantly, the surface of the $\mathrm{Cu}(111)$ thin film is ultraflat with an RMS roughness of $0.308 \mathrm{~nm}$ in the image region of $25 \mu \mathrm{m}^{2}$, as shown by the AFM image (Figure 2c, Supporting Information Figure S16). In addition, we have carried out $2 \mathrm{D}$ mapping of $\mathrm{Cu}$ thin film by electron backscattering diffraction (EBSD) (Figure 2d, Supporting Information Figure $\mathrm{S} 17)$. The $\mathrm{Cu}(111)$ pole figure of EBSD shows three evenly distributed points, which indicates the single orientation of $\mathrm{Cu}(111)$ without in-plane twinning.

In addition to EBSD maps, the X-ray diffraction (XRD) pattern $(2 \theta$ scan $)$ of the $\mathrm{Cu}$ /sapphire indicated an out-of-plane orientation of (111) over the whole wafer (Figure 2e, Supporting Information Figure S18). We chose $\mathrm{Cu}(200)$ and $\mathrm{Al}_{2} \mathrm{O}_{3}(02 \overline{2} 4)$ as Bragg positions and performed a $\varphi$ scan by rotating the sample normal to the surface with high-resolution XRD (HRXRD) (Figure 2f). The diffraction peaks of both $\mathrm{Cu}$ and sapphire appear periodically at intervals of $120^{\circ}$ and have a quite narrow full width at half-maximum (fwhm). Since a single (111) pole has a 3-fold trigonal symmetry, we conclude that the $\mathrm{Cu}(111)$ is single crystalline without in-plane twin structures.

Moreover, we can identify the epitaxial orientation relationship (OR) from the peak position of $\mathrm{Cu}$ and sapphire in the $\varphi$ scan (Figure $2 \mathrm{f}$ ), as schematically shown in Figure $2 \mathrm{~g}$ : $\mathrm{OR} \equiv$ $(111)_{\mathrm{Cu}}\left\|(0001)_{\alpha \text {-Al2O3}} \wedge\langle\overline{1} 10\rangle_{\mathrm{Cu}}\right\|\langle 10 \overline{1} 0\rangle_{\alpha-\mathrm{Al} 2 \mathrm{O} 3} . \mathrm{Cu}$ is under at most $\sim 6.7 \%$ tensile epitaxial stress in both $[1 \overline{1} 0]$ and $[11 \overline{2}]$ directions in this OR. The epitaxial relationship was further proven by cross-sectional transmission electron microscopy (TEM), including the atomically resolved scanning transmission electron microscopy (STEM) characterization of the interface regions between $\mathrm{Cu}$ and sapphire (Figure $2 \mathrm{~h}$ ), and the selected area electron diffraction (SAED) patterns of the $\mathrm{Cu}$ film (Figure 2i) and sapphire (Figure $2 \mathrm{j}$ ). A Cu $\mathrm{Cu}_{2} \mathrm{O}$ buffer layer with a thickness of 

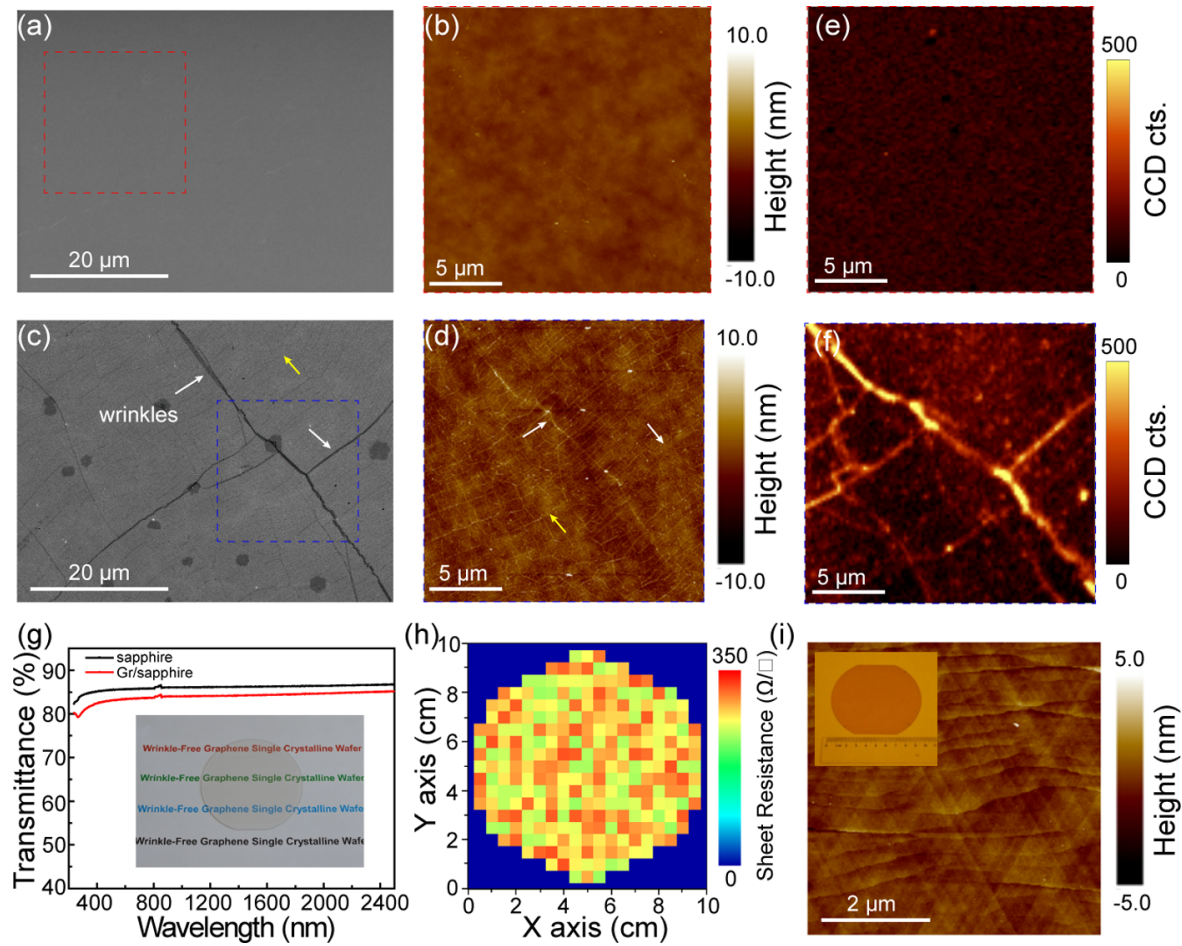

Figure 4. Wafer-scale transfer of wrinkle-free graphene onto target substrates. (a) SEM image of wrinkle-free graphene transferred onto a $\mathrm{SiO}{ }_{2} / \mathrm{Si}$ substrate. (b) AFM image of the region marked in a red frame in a. (c) SEM image of graphene with wrinkles on a $\mathrm{SiO}_{2} / \mathrm{Si}_{\mathrm{substrate}}$ (d) AFM image of the region marked in a blue frame in c. The white arrow indicates the growth-induced wrinkles, and yellow arrow indicates transferinduced wrinkles. (e) Raman D map of wrinkle-free graphene in a. (f) Raman D map of wrinkled graphene in c. (g) Transmittance curve of sapphire and graphene/sapphire. Inset shows a photograph of the 4 in. graphene/sapphire. (h) Sheet resistance map of the 4 in. graphene/ sapphire. The blue color marks the area without graphene. (i) AFM image and photograph (inset) of a Cu(111)/sapphire after three cycles of graphene growth and bubbling transfer.

1-2 $\mathrm{nm}$ exists between $\mathrm{Cu}$ and the oxygen-pretreated sapphire substrate (Supporting Information Figure S19).

In a control experiment, a $\mathrm{Cu}$ thin film sputtered on sapphire without oxygen annealing pretreatment shows grain boundaries with deep thermal grooves (Supporting Information Figure S20), and the in-plane twinning is verified by a $\varphi$ scan of HRXRD (Supporting Information Figure S21) and an EBSD map (Supporting Information Figure S22). The orientation relationship between $\mathrm{Cu}$ and $\alpha-\mathrm{Al}_{2} \mathrm{O}_{3}$ (without oxygen pretreatment) is the same as that of $\alpha-\mathrm{Al}_{2} \mathrm{O}_{3}$ (with oxygen pretreatment), yet no intermediate layer is observed at the interface regions (Supporting Information Figure S23). We believe that the preannealing of sapphire in an oxygen atmosphere contributes to the formation of more oxygen-terminated sapphire surface, as indicated by the Auger electron spectroscopy (AES) and X-ray photoelectron spectroscopy (XPS) measurement (Supporting Information Figures S24, S25). The oxygen termination might be beneficial for the formation of a uniform ultrathin $\mathrm{Cu}_{2} \mathrm{O}$ buffer layer, ${ }^{40}$ which contributes to the relief of large epitaxial stress between $\mathrm{Cu}$ and sapphire, the key to wafer-scale epitaxy of a twinfree single-crystal $\mathrm{Cu}(111)$ thin film (Supporting Information Figures S26, S27). ${ }^{40}$

As mentioned above, the interaction between graphene and $\mathrm{Cu}$ is related to $\mathrm{Cu}$ crystallographic orientation. Strong graphene-substrate interplay allows strain retaining instead of wrinkle formation. We investigated the state of graphene on $\mathrm{Cu}(111)$ and $\mathrm{Cu}(100)$ to explain the difference in wrinkling behavior by Raman spectroscopy due to its feasibility for simultaneous strain and doping analysis. ${ }^{43-45}$ The representative Raman spectra of graphene $/ \mathrm{Cu}(111)$ thin film and graphene $/ \mathrm{Cu}(100)$ are shown in Figure 3a. Compared with the Raman spectrum of intrinsic graphene, the $2 \mathrm{D}$ band of graphene on $\mathrm{Cu}(111)$ thin film is obviously weakened, while it remains strong on the $\mathrm{Cu}(100)$ substrate. Moreover, the $\mathrm{G}$ and $2 \mathrm{D}$ bands blue-shift for the samples on both $\mathrm{Cu}(111)$ and $\mathrm{Cu}(100)$, while the bands shift more on $\mathrm{Cu}(111)$.

The interaction of graphene- $\mathrm{Cu}$ can be quantitatively described using the charge transfer, which can be detected as the doping state of graphene. For example, it is reported that graphene on $\mathrm{Cu}(111)$ is $\mathrm{n}$-doped by angle-resolved photoemission spectroscopy (ARPES) with a Fermi level $\left(E_{\mathrm{F}}\right)$ shift of $\sim-300 \mathrm{meV}^{46}$ In contrast, graphene is supposed to be weakly physisorbed on $\mathrm{Cu}(100)$ foil with a doping less than $110 \mathrm{meV}$ derived from the microspot ARPES. ${ }^{47}$ On the other hand, Raman spectroscopy provides an indicator for the doping effect of graphene, where strong doping induces an obvious decreased intensity ratio of the $2 \mathrm{D}$ and $\mathrm{G}$ bands $\left(I_{2 \mathrm{D}} / I_{\mathrm{G}}\right){ }^{48}$ As shown in Figure $3 \mathrm{~b}$, the mean values of $I_{2 \mathrm{D}} / I_{\mathrm{G}}$ on $\mathrm{Cu}(111)$ and $\mathrm{Cu}(100)$ are 1.54 and 2.87, respectively, which indicates that graphene on $\mathrm{Cu}(111)$ is more heavily doped than graphene on $\mathrm{Cu}(100)$. Moreover, the STM test is also adopted to verify the interaction difference of graphene $/ \mathrm{Cu}(111)$ vs graphene $/ \mathrm{Cu}(100)$ (Supporting Information Figure S28).

As a consequence of weak interaction of graphene on $\mathrm{Cu}(100)$, the wrinkles form during the cooling process for strain relief. ${ }^{24,49}$ Raman spectroscopy was also used to investigate the remaining strain of graphene on $\mathrm{Cu}(100)$ and $\mathrm{Cu}(111)$, in which compressive strain causes the blue-shift of both $\mathrm{G}$ and $2 \mathrm{D}$ bands, while tensile strain causes the reverse. ${ }^{44}$ The blue-shift of the $\mathrm{G}$ and $2 \mathrm{D}$ peaks indicates the possible biaxially compressive strain 
in the graphene lattice (Figure 3a), since uniaxial strain will cause splitting of the peaks. ${ }^{44,50}$ To exclude the doping effect by underlying $\mathrm{Cu}$ substrates, we conducted the correlation analysis of the $\mathrm{G}$ and 2D mode based on the difference in ratio of the shift of $\omega_{2 \mathrm{D}}$ and $\omega_{\mathrm{G}}\left(\Delta \omega_{2 \mathrm{D}} / \Delta \omega_{\mathrm{G}}\right){ }^{51}$ Biaxially strained graphene shows a much larger ratio of $\left(\Delta \omega_{2 \mathrm{D}} / \Delta \omega_{\mathrm{G}}\right)-\varepsilon^{52,53}$ than that induced by charge doping. ${ }^{54,55}$ We plotted $\Delta \omega_{\mathrm{G}}$ and $\Delta \omega_{2 \mathrm{D}}$ (Figure 3c). The dots measured from graphene/ $\mathrm{Cu}(111)$ mainly distributed at the upper right compared with those from graphene $/ \mathrm{Cu}(100)$, which reveals that graphene on $\mathrm{Cu}(111)$ is more compressively strained than that on $\mathrm{Cu}(100)$. These observations clearly indicate that strong interfacial coupling of graphene with $\mathrm{Cu}(111)$ enables strain energy retention in the graphene lattice and prevents wrinkle formation.

To further clarify the kinetic process of graphene wrinkle formation on various crystallographic planes, we performed large-scale molecular dynamics (MD) simulations using the massively parallel simulator (LAMMPS) to mimic their CVD conditions. As shown in Figure 3d-i, we present the morphology snapshots of graphene at different stages. With the imposed thermal strain during cooling, the initially flat graphene forms a number of wrinkles on the $\mathrm{Cu}$ (100) surface (Figure 3d). At $300 \mathrm{~K}$, those wrinkles begin to coalescence to form a large wrinkle along the $\mathrm{Cu}[001]$ direction (Figure $3 \mathrm{~g}$ and Supporting Video $S 1$, the zigzag direction of graphene). If the graphene is placed on the $\mathrm{Cu}(110)$ surface, it forms bubbles at first (Figure 3e), and then these bubbles collapse and transform into a large wrinkle along the $\mathrm{Cu}[-110]$ direction (Figure $3 \mathrm{~h}$ and Supporting Video S2, also the zigzag direction of graphene). In contrast, the graphene on the $\mathrm{Cu}(111)$ plane behaves quite differently: It forms a patterned "superlattice" at the beginning (Figure 3f) and then gradually flattens out at a sufficiently long time (Figure $3 \mathrm{i}$ and Supporting Video S3). The superlattice resembles the moiré pattern of aligned graphene on $\mathrm{Cu}(111)$, as shown in Figure S28. ${ }^{56}$ We calculate the binding energy and the wrinkle height as a function of different crystallographic planes (Figure $3 \mathrm{j}$ ). A binding energy of $24.1 \mathrm{meV} / \AA^{2}$ for graphene on the $\mathrm{Cu}(111)$ surface is found and is the greatest among the three planes. More importantly, the binding energy of graphene $/ \mathrm{Cu}(111)$ plane is large enough to suppress the bending energy introduced by wrinkles, which could be introduced by thermal undulation as the bending stiffness of graphene is ultralow. ${ }^{57}$

The flat and wrinkle-free graphene/ $\mathrm{Cu}(111)$ thin film is beneficial for the transfer of ultrasmooth graphene films with the least transfer-induced wrinkles. ${ }^{20,21}$ We used a poly-(methyl methacrylate) (PMMA)-mediated bubbling transfer method to retain the single-crystal $\mathrm{Cu}(111)$ substrate. ${ }^{5}$ Both the SEM image (Figure $4 \mathrm{a}$ ) and AFM image (Figure $4 \mathrm{~b}$ ) of graphene transferred onto the $\mathrm{SiO}_{2} / \mathrm{Si}$ substrate indicate a uniform monolayer without visible wrinkles. In contrast, the SEM image of transferred graphene grown on $\mathrm{Cu}(100)$ foil shows large amounts of wrinkles with varied widths (Figure 4c). Those larger wrinkles (white arrows) derive from growth-induced wrinkles, and the small wrinkles (yellow arrows) are more likely induced by the transfer process since the surface of $\mathrm{Cu}$ foil is very rough (Figure $1 \mathrm{~d}$ ). ${ }^{20,58}$ The ubiquitous wrinkles induced by the transfer process are obvious in the AFM image (Figure 4d). The quality of graphene with and without wrinkles was then evaluated using Raman spectroscopy. The Raman D band mapping of wrinkle-free graphene in Figure 4e is rather uniform and near the background level, and the $\mathrm{G}$ band, $2 \mathrm{D}$ band, and the ratio mapping all prove the high-quality monolayer graphene feature (Supporting Information Figure S31). In contrast, a strong D band exists and distributes well consistent with the growth-induced wrinkles (Figure 4f), which indicates a wrinkle with high enough curvature to locally enable the radial breathing mode. ${ }^{59}$ The electronic quality of wrinkle-free single-crystal graphene was evaluated by transport measurements, showing a room-temperature mobility as high as $\sim 11000 \mathrm{~cm}^{2} \mathrm{~V}^{-1} \mathrm{~s}^{-1}$, which is among the best results of CVD-grown graphene. ${ }^{60,61}$ Notably, the mobility of wrinkle-free graphene is much higher than that of graphene with wrinkles (Supporting Information Figure S32).

The wafer-scale wrinkle-free graphene single crystal was also transferred onto a 500- $\mu$ m-thick $c$-plane sapphire substrate (Figure $4 \mathrm{~g}$ ). The graphene layer exhibits $\sim 2.34 \%$ absorption at $550 \mathrm{~nm}$ (Figure $4 \mathrm{~g}$ ), consistent with the ideal transmittance for monolayer graphene. The distribution of sheet resistance is uniform with an average value of $\sim 275 \Omega / \square$ (Figure $4 \mathrm{~h}$ ), much smaller than most reported monolayer graphene (Supporting Information Figure S33, Table S1). Benefitting from the etchingfree transfer process, we repeated the growth and transfer for three cycles with the same $\mathrm{Cu}(111)$ /sapphire. The $\mathrm{Cu}(111)$ thin film stays flat and clean, and graphene grown repeatedly also shows no degradation in quality (Figure 4i, Supporting Information Figure S34).

\section{CONCLUSION}

To conclude, we demonstrated the wafer-scale growth of wrinklefree graphene single crystals on $\mathrm{Cu}(111)$ thin film. The wrinklefree feature of graphene is attributed to the strong interfacial coupling of graphene with $\mathrm{Cu}(111)$ that enables strain energy retention in the graphene lattice instead of wrinkle formation. The concept of engineering the thermal expansion and interaction of metal substrates may extend to many other growth substrates, such as $\mathrm{Ni}$, $\mathrm{Pt}$, or their alloys, for wrinkle-free graphene growth or other two-dimensional analogues, such as h-BN.

\section{METHODS}

Single-Crystal $\mathrm{Cu}(111)$ Thin Film Epitaxy on Sapphire. The $\mathrm{Cu}$ thin film was deposited on a single-crystal sapphire (4 in., $c$ plane with misorientation $<0.5^{\circ}, 500 \mu \mathrm{m}$ thickness, Epi-ready with $\mathrm{Ra}<0.2 \mathrm{~nm}$ ) by a radio frequency $(\mathrm{RF})$ sputtering technique using a $\mathrm{PVD}$ equipment (Sputter film, SF2). An RF power of $500 \mathrm{~W}$ was applied to deposit $\mathrm{Cu}$ thin film at the deposition rate of $0.2 \mathrm{~nm} \mathrm{~s}^{-1}$, with a basal pressure of $4 \times 10^{-4}$ Torr. A $500-\mathrm{nm}$-thick $\mathrm{Cu}$ thin film was obtained after $30 \mathrm{~min}$ of deposition. Before deposition, the sapphire substrate was annealed at $1000{ }^{\circ} \mathrm{C}$ for $12 \mathrm{~h}$ in a pure oxygen atmosphere. Also, the unannealed sapphire is used to directly deposit the $\mathrm{Cu}$ film for comparison. For convenience, $\mathrm{Cu}$ deposited on sapphire with preannealing in oxygen was defined as $\mathrm{Cu}$ /sapphire-(A), while the unannealed one, as $\mathrm{Cu}$ /sapphire-(NA). The $\mathrm{Cu} /$ sapphire was then annealed at $1000{ }^{\circ} \mathrm{C}$ with $500 \mathrm{sccm} \mathrm{Ar}$ and $10 \mathrm{sccm} \mathrm{H}_{2}$ at atmospheric pressure using a tube furnace (Thermal Scientific) for $1 \mathrm{~h}$ to increase the crystallinity of the $\mathrm{Cu}$ thin film.

Wrinkle-Free Graphene Single-Crystal Growth. The $\mathrm{Cu}(111)$ / sapphire was heated to $1000{ }^{\circ} \mathrm{C}$ with $500 \mathrm{sccm} \mathrm{Ar}$ and $10 \mathrm{sccm} \mathrm{H}$ at atmospheric pressure; then $10 \mathrm{sccm} \mathrm{CH}_{4}(0.1 \%$ diluted in $\mathrm{Ar}$ ) was introduced for graphene growth. Usually a $30 \mathrm{~min}$ growth results in graphene domains with a size of $\sim 50 \mu \mathrm{m}$, and fully covered graphene was produced by extending the growth time to $\sim 2 \mathrm{~h}$. After growth, $\mathrm{CH}_{4}$ gas flow was switched off and the sample was cooled to room temperature. Commercially available rolled $\mathrm{Cu}$ foil $(25 \mu \mathrm{m}$ thick, Alfa Aesar \#46365, mostly 100-oriented) was used as reference. The $\mathrm{Cu}$ foil was first electrochemically polished in electrolyte solution composed of phosphoric acid and ethylene glycol $(\mathrm{v} / \mathrm{v}=3: 1)$ with a voltage of $2 \mathrm{~V}$ for $30 \mathrm{~min}$. The growth condition of graphene on $\mathrm{Cu}$ foil is the same as that of $\mathrm{Cu}(111)$ thin film.

Graphene Transfer. PMMA was spin coated on graphene/Cu at a speed of $2000 \mathrm{rpm}$ for $1 \mathrm{~min}$. The PMMA/graphene film was detached 
from $\mathrm{Cu}$ by an electrochemical bubbling transfer method using $0.1 \mathrm{M}$ $\mathrm{NaOH}-(\mathrm{aq})$ as electrolyte and $\mathrm{Pt}$ foil as the counter electrode. After detaching, the PMMA/graphene film was merged into water to clean the residues. The PMMA/graphene was then rinsed in DI water several times and attached to target substrates. After drying in air overnight, the PMMA was removed by hot acetone.

Characterization. Optical Measurement. Optical microscopy was conducted on a Nikon Olympus LV100ND. To measure the strain of graphene on $\mathrm{Cu}$ substrates, Raman spectra were collected on a JY Horiba HR800 Raman system with a $514 \mathrm{~nm}(2.41 \mathrm{eV})$ line from an $\mathrm{Ar}^{+}$ laser with a laser spot size of $1 \mu \mathrm{m}$. The laser power on the sample was kept below $1 \mathrm{~mW}$ to avoid graphene heating. A $100 \times$ objective and 600 lines/mm grating (spectral resolution was about $1 \mathrm{~cm}^{-1}$ ) were used to collect the Raman signal. The test was conducted immediately after graphene growth to exclude possible decoupling. To measure the Raman spectra of graphene transferred onto the $\mathrm{SiO}_{2} / \mathrm{Si}$ substrate, a Witec Raman system (alpha RSA300+) with a $488 \mathrm{~nm}$ laser was used with a laser spot size of $1 \mu \mathrm{m}$. The spatial resolution is about $350 \mathrm{~nm}$. A $100 \times$ objective and 600 lines/mm grating (spectral resolution was about $3 \mathrm{~cm}^{-1}$ ) were used to collect the Raman signal. The transmittance measurement was conducted using a UV-vis-NIR PerkinElmer Lambda 950 spectrophotometer.

XRD Characterization. A PANalytical X'pert PRO high-resolution $\mathrm{X}$-ray diffractometer using $\mathrm{Cu} \mathrm{K} \alpha$ radiation was employed. Different geometrical setups of the instrument were used depending on the scanning procedure. The high-resolution mode enables an angle resolution of $0.001^{\circ}$.

SEM and EBSD Measurement. SEM images were obtained on a Hitachi S4800 field-emission scanning electron microscope. EBSD measurements were carried out on a ULVAC-PHI (PHI 710) Auger system equipped with an EBSD probe (EDAX, DigView). The EBSD test was operated at $10 \mathrm{kV}$ voltage and $10 \mathrm{nA}$ current. The spot size was $20 \mathrm{~nm}$.

TEM Measurement. The cross-sectional TEM specimen was fabricated using a focused ion beam system (FET Strata DB 235). The thickness of the specimen foil was less than $100 \mathrm{~nm}$. TEM and SAED were performed on the TEI Tecnai F20 operated at $200 \mathrm{kV}$. The STEM images were acquired at an aberration-corrected FEI microscope (Titan Cubed Themis G2) operated at $300 \mathrm{kV}$ with a beam current of $0.2 \mathrm{nA}$, convergence semiangle of $25 \mathrm{mrad}$, and collection semiangle snap of 80-379 mrad.

AFM and STM Measurement. The AFM morphology image was obtained on a Bruker Dimension Icon using the tapping mode. STM measurement was conducted with an Omicron-VT-STM system. The graphene $/ \mathrm{Cu}(111)$ sample was annealed at $673 \mathrm{~K}$ for $4 \mathrm{~h}$ before measurement at $293 \mathrm{~K}$. All of the STM topographic images were obtained in constant-current mode. The $\mathrm{d} I / \mathrm{d} V$ spectra were acquired by a lock-in amplifier, while the sample bias was modulated by a $10 \mathrm{mV}$ (RMS), $1327 \mathrm{~Hz}$ sinusoidal signal under open-feedback condition.

AES and XPS Measurement. AES was conducted on a ULVAX-PHI (PHI 710) Auger system, with the voltage of $10 \mathrm{kV}$ and beam current of $10 \mathrm{nA}$. XPS was conducted on an XPS Kratos Axis Ultra-DLD spectrophotometer with monochromatic $\mathrm{Al} \mathrm{X}$-ray at low pressures of $5 \times 10^{-9}$ to $1 \times 10^{-8}$ Torr.

Low-Energy Electron Diffraction (LEED) Measurement. The crystalline structure of graphene grown on $\mathrm{Cu}(111) /$ sapphire was characterized by microregion LEED $(\mu$-LEED, selected area $\sim 5 \mu \mathrm{m})$ in an Elmitec LEEM-III system (UHV base pressure $<10^{-10}$ Torr). The electron energy for LEED was fixed to $50 \mathrm{eV}$.

Sheet Resistance Measurement. The sheet resistance was measured using a four-probe system (CDE ResMap 178) based on the four-point probe method to eliminate contact resistance. Four metal probes were aligned in a line at intervals of $1 \mathrm{~mm}$.

Electrical Property Measurements. The graphene samples (grown on both $\mathrm{Cu}(100)$ foil and $\mathrm{Cu}(111)$ thin film) were transferred onto $\mathrm{SiO}_{2} / \mathrm{Si}$ substrates with marks for alignments. Then, graphene samples were etched in Hall bar geometry (channel width of $2 \mu \mathrm{m}$, length between bars of $5.5 \mu \mathrm{m}$ ) by using a PMMA etch mask from electron beam lithography (EBL) (Raith $150 \mathrm{~s}$ ) and reactive ion etching (RIE) $\mathrm{O}_{2}$ etching (Trion Technology Minilock III). Finally, after using EBL to design a PMMA mask, the samples were contacted with $5 \mathrm{~nm}$ Ti and $90 \mathrm{~nm}$ Au using an electron beam evaporator (Kurte J. Lesker AXXIS) followed by a standard lift-off technique. Electric transport was carried out at room temperature in a vacuum probe stration (Lakeshore TTP-4) using a Keithly Semiconductor Characterization System (4200-SCS).

Theoretical Calculation. We consider monolayer graphene adhering to various crystallographic planes of copper substrates, mimicking their CVD condition. The graphene is initially flat at the depositing temperature and is stress free. As the temperature decreases, the sheet is subjected to compressive stress due to the thermal mismatch between the graphene and the substrate. We perform large-scale $\mathrm{MD}$ simulations using the massively parallel simulator (LAMMPS) ${ }^{62}$ to understand the kinetic process. The adaptive intermolecular reactive empirical bond order (AIREBO) ${ }^{63}$ potential is used to describe the interaction among carbon atoms. The $\mathrm{Cu}-\mathrm{Cu}$ interactions in the $\mathrm{Cu}$ substrate are represented by the embedded atom method (EAM) potential, ${ }^{64}$ which can accurately describe the structural and mechanical properties of $\mathrm{Cu}$ and is broadly used. The interaction between graphene and $\mathrm{Cu}$ substrate is described by the Lennard-Jones (L-J) potential $V_{(r)}=4 \varepsilon-\left(\sigma^{12} / r^{12}-\right.$ $\left.\sigma^{6} / r^{6}\right)$. Here $\varepsilon$ and $\sigma$ are two L-J parameters that determine the depth of the potential well and the position of zero potential, respectively, and $r$ is the distance between two atoms. In our MD simulations, we use $\varepsilon=$ $0.0168 \mathrm{eV}$ and $\sigma=2.2 \AA$. Such a potential is widely used to capture the van der Waals interaction between graphene and the Cu substrate. ${ }^{65,66}$ When the film and substrate system cools from $1300 \mathrm{~K}$ to room temperature $(300 \mathrm{~K})$, it imposes a thermal mismatch strain, which is approximately $2.5 \%$. We impose the thermal strain and then relax the system at $300 \mathrm{~K}$ to examine the dynamic profile of the graphene. Periodical boundary condition was applied in the $x$ and $y$ directions (Supporting Information Figure S30). The Cu substrate is sufficiently thick $(4 \mathrm{~nm})$ to avoid boundary interference. We simulated the cases of graphene on three crystallographic $\mathrm{Cu}$ substrate surfaces, $\mathrm{Cu}(100)$, $\mathrm{Cu}(110)$, and $\mathrm{Cu}(111)$ surface, whose areas are $66.6 \mathrm{~nm}$ by $61.7 \mathrm{~nm}$, $66.6 \mathrm{~nm}$ by $66.9 \mathrm{~nm}$, and $67.6 \mathrm{~nm}$ by $66.9 \mathrm{~nm}$, respectively. The stable morphology is obtained until the relative variation of potential energy of the system is less than $0.002 \%$. All our simulations were run in an NVT ensemble using a Nose-Hoover thermostat, and the time step was $0.5 \mathrm{fs}$.

\section{ASSOCIATED CONTENT}

\section{Supporting Information}

The Supporting Information is available free of charge on the ACS Publications website at DOI: 10.1021/acsnano.7b06196.

Additional figures and tables as described in the text (PDF)

Videos of molecular dynamics stimulation of wrinkle formation (AVI)

(AVI)

(AVI)

\section{AUTHOR INFORMATION}

\section{Corresponding Authors}

*E-mail (Y. Wei): yujie_wei@lnm.imech.ac.cn.

*E-mail (Z. Liu): zfliu@pku.edu.cn.

*E-mail (H. Peng): hlpeng@pku.edu.cn.

\section{ORCID}

Bing Deng: 0000-0003-0530-8410

Yanfeng Zhang: 0000-0003-1319-3270

Jin Zhang: 0000-0003-3731-8859

Hongqi Xu: 0000-0001-6434-2569

Qiang Fu: 0000-0001-5316-6758

Peng Gao: 0000-0003-0860-5525

Yujie Wei: 0000-0002-3213-7891

Zhongfan Liu: 0000-0003-0065-7988

Hailin Peng: 0000-0003-1569-0238 


\section{Author Contributions}

H.L.P., Z.F.L., and B.D. conceived the experiment. H.L.P. and Z.F.L. supervised the project. B.D. conducted the $\mathrm{Cu}(111)$ single-crystalline fabrication, the wrinkle-free single-crystal graphene growth, and graphene transfer. B.D. took and analyzed the OM, SEM, UV-vis, AFM, XRD, and EBSD. Z.Q.P. and Y.J.W. conducted the theoretical calculation. S.L.C. conducted the TEM measurements under the supervision of P.G. X.L., M.X.L, X.H.Q., Y.Q., and Y.F.Z. conducted the STM measurement. C.X.M. and Q.F. conducted the LEED measurement. J.Y.L., N.K., and H.Q.X. conducted the transport measurement. J.X.W. and J.Z. conducted the Raman test. B.D. and H.L.P. wrote the paper. All the authors discussed the results and commented on the manuscript.

\section{Notes}

The authors declare no competing financial interest.

\section{ACKNOWLEDGMENTS}

We thank Shishu Zhang for the help in Raman test, and Dr. Li Lin for the beneficial discussions. This work was financially supported by the National Basic Research Program of China (Nos. 2016YFA0200101 and 2014CB932500), the National Natural Science Foundation of China (Nos. 51432002, 51520105003, 21525310, 11425211, 21603045, 51672007, and 51502007), Beijing Municipal Science \& Technology Commission (Nos. Z161100002116002 and Z161100002116021), Wenghongwu Keyan Yuanchuang jijin of Peking University (No. WHW201503), CAS-PKU Pioneer Cooperation Team, and Supercomputing Center of CAS.

\section{REFERENCES}

(1) Li, X.; Cai, W.; An, J.; Kim, S.; Nah, J.; Yang, D.; Piner, R.; Velamakanni, A.; Jung, I.; Tutuc, E.; Banerjee, S. K.; Colombo, L.; Ruoff, R. S. Large-Area Synthesis of High-Quality and Uniform Graphene Films on Copper Foils. Science 2009, 324, 1312-1314.

(2) Li, X. S.; Colombo, L.; Ruoff, R. S. Synthesis of Graphene Films on Copper Foils by Chemical Vapor Deposition. Adv. Mater. 2016, 28, 6247-6252.

(3) Chae, S. J.; Gunes, F.; Kim, K. K.; Kim, E. S.; Han, G. H.; Kim, S. M.; Shin, H. J.; Yoon, S. M.; Choi, J. Y.; Park, M. H.; Yang, C. W.; Pribat, D.; Lee, Y. H. Synthesis of Large-Area Graphene Layers on Poly-Nickel Substrate by Chemical Vapor Deposition: Wrinkle Formation. Adv. Mater. 2009, 21, 2328-2333.

(4) Kim, K. S.; Zhao, Y.; Jang, H.; Lee, S. Y.; Kim, J. M.; Kim, K. S.; Ahn, J. H.; Kim, P.; Choi, J. Y.; Hong, B. H. Large-Scale Pattern Growth of Graphene Films for Stretchable Transparent Electrodes. Nature 2009, 457, 706-710.

(5) Gao, L. B.; Ren, W. C.; Xu, H. L.; Jin, L.; Wang, Z. X.; Ma, T.; Ma, L. P.; Zhang, Z. Y.; Fu, Q.; Peng, L. M.; Bao, X. H.; Cheng, H. M. Repeated Growth and Bubbling Transfer of Graphene with Millimetre-Size Single-Crystal Grains using Platinum. Nat. Commun. 2012, 3, 699.

(6) Novoselov, K. S.; Fal'ko, V. I.; Colombo, L.; Gellert, P. R.; Schwab, M. G.; Kim, K. A Roadmap for Graphene. Nature 2012, 490, 192-200.

(7) Bonaccorso, F.; Sun, Z.; Hasan, T.; Ferrari, A. C. Graphene Photonics and Optoelectronics. Nat. Photonics 2010, 4, 611-622.

(8) Hao, Y. F.; Bharathi, M. S.; Wang, L.; Liu, Y. Y.; Chen, H.; Nie, S.; Wang, X. H.; Chou, H.; Tan, C.; Fallahazad, B.; Ramanarayan, H.; Magnuson, C. W.; Tutuc, E.; Yakobson, B. I.; McCarty, K. F.; Zhang, Y. W.; Kim, P.; Hone, J.; Colombo, L.; Ruoff, R. S. The Role of Surface Oxygen in the Growth of Large Single-Crystal Graphene on Copper. Science 2013, 342, 720-723.

(9) Xu, X.; Zhang, Z.; Qiu, L.; Zhuang, J.; Zhang, L.; Wang, H.; Liao, C.; Song, H.; Qiao, R.; Gao, P.; Hu, Z.; Liao, L.; Liao, Z.; Yu, D.; Wang, E.; Ding, F.; Peng, H.; Liu, K. Ultrafast Growth of Single-Crystal Graphene Assisted by a Continuous Oxygen Supply. Nat. Nanotechnol. 2016, 11, 930-935.
(10) Zhang, Y. F.; Gao, T.; Gao, Y. B.; Xie, S. B.; Ji, Q. Q.; Yan, K.; Peng, H. L.; Liu, Z. F. Defect-like Structures of Graphene on Copper Foils for Strain Relief Investigated by High-Resolution Scanning Tunneling Microscopy. ACS Nano 2011, 5, 4014-4022.

(11) Kang, J. H.; Moon, J.; Kim, D. J.; Kim, Y.; Jo, I.; Jeon, C.; Lee, J.; Hong, B. H. Strain Relaxation of Graphene Layers by $\mathrm{Cu}$ Surface Roughening. Nano Lett. 2016, 16, 5993-5998.

(12) Zhu, W. J.; Low, T.; Perebeinos, V.; Bol, A. A.; Zhu, Y.; Yan, H. G.; Tersoff, J.; Avouris, P. Structure and Electronic Transport in Graphene Wrinkles. Nano Lett. 2012, 12, 3431-3436.

(13) Mun, J. H.; Cho, B. J. Synthesis of Monolayer Graphene Having a Negligible Amount of Wrinkles by Stress Relaxation. Nano Lett. 2013, 13, 2496-2499.

(14) Mun, J. H.; Oh, J. G.; Bong, J. H.; Xu, H.; Loh, K. P.; Cho, B. J. Wrinkle-Free Graphene with Spatially Uniform Electrical Properties Grown on Hot-Pressed Copper. Nano Res. 2015, 8, 1075-1080.

(15) Vasic, B.; Zurutuza, A.; Gajic, R. Spatial Variation of Wear and Electrical Properties across Wrinkles in Chemical Vapour Deposition Graphene. Carbon 2016, 102, 304-310.

(16) Zhang, Y. H.; Wang, B.; Zhang, H. R.; Chen, Z. Y.; Zhang, Y. Q.; Wang, B.; Sui, Y. P.; Li, X. L.; Xie, X. M.; Yu, G. H.; Jin, Z.; Liu, X. Y. The Distribution of Wrinkles and Their Effects on the Oxidation Resistance of Chemical Vapor Deposition Graphene. Carbon 2014, 70, 81-86.

(17) Chen, S. S.; Li, Q. Y.; Zhang, Q. M.; Qu, Y.; Ji, H. X.; Ruoff, R. S.; Cai, W. W. Thermal Conductivity Measurements of Suspended Graphene with and without Wrinkles by Micro-Raman Mapping. Nanotechnology 2012, 23, 365701-365704.

(18) Lin, Y. M.; Valdes-Garcia, A.; Han, S. J.; Farmer, D. B.; Meric, I.; Sun, Y. N.; Wu, Y. Q.; Dimitrakopoulos, C.; Grill, A.; Avouris, P.; Jenkins, K. A. Wafer-Scale Graphene Integrated Circuit. Science 2011, 332, 1294-1297.

(19) Lee, J. H.; Lee, E. K.; Joo, W. J.; Jang, Y.; Kim, B. S.; Lim, J. Y.; Choi, S. H.; Ahn, S. J.; Ahn, J. R.; Park, M. H.; Yang, C. W.; Choi, B. L.; Hwang, S. W.; Whang, D. Wafer-Scale Growth of Single-Crystal Monolayer Graphene on Reusable Hydrogen-Terminated Germanium. Science 2014, 344, 286-289.

(20) Kim, S. J.; Choi, T.; Lee, B.; Lee, S.; Choi, K.; Park, J. B.; Yoo, J. M.; Choi, Y. S.; Ryu, J.; Kim, P.; Hone, J.; Hong, B. H. Ultraclean Patterned Transfer of Single-Layer Graphene by Recyclable Pressure Sensitive Adhesive Films. Nano Lett. 2015, 15, 3236-3240.

(21) Wang, B.; Huang, M.; Tao, L.; Lee, S. H.; Jang, A. R.; Li, B. W.; Shin, H. S.; Akinwande, D.; Ruoff, R. S. Support-Free Transfer of Ultrasmooth Graphene Films Facilitated by Self-Assembled Monolayers for Electronic Devices and Patterns. ACS Nano 2016, 10, 1404-1410.

(22) Bao, W. Z.; Miao, F.; Chen, Z.; Zhang, H.; Jang, W. Y.; Dames, C.; Lau, C. N. Controlled Ripple Texturing of Suspended Graphene and Ultrathin Graphite Membranes. Nat. Nanotechnol. 2009, 4, 562-566.

(23) Yoon, D.; Son, Y. W.; Cheong, H. Negative Thermal Expansion Coefficient of Graphene Measured by Raman Spectroscopy. Nano Lett. 2011, 11, 3227-3231.

(24) Hattab, H.; N'Diaye, A. T.; Wall, D.; Klein, C.; Jnawali, G.; Coraux, J.; Busse, C.; van Gastel, R.; Poelsema, B.; Michely, T.; Heringdorf, F. J. M. Z.; Horn-von Hoegen, M. Interplay of Wrinkles, Strain, and Lattice Parameter in Graphene on Iridium. Nano Lett. 2012, $12,678-682$

(25) N'Diaye, A. T.; van Gastel, R.; Martinez-Galera, A. J.; Coraux, J.; Hattab, H.; Wall, D.; zu Heringdorf, F. J. M.; Horn-von Hoegen, M.; Gomez-Rodriguez, J. M.; Poelsema, B.; Busse, C.; Michely, T. In-situ Observation of Stress Relaxation in Epitaxial Graphene. New J. Phys. 2009, 11, 113056-113070.

(26) Batzill, M. The surface science of graphene: Metal interfaces, CVD synthesis, Nanoribbons, Chemical Modifications, and Defects. Surf. Sci. Rep. 2012, 67, 83-115.

(27) Hakkinen, H.; Manninen, M. Computer-Simulation of Disordering and Premelting of Low-Index Faces of Copper. Phys. Rev. B: Condens. Matter Mater. Phys. 1992, 46, 1725-1742.

(28) Hakkinen, H.; Landman, U. Superheating, Melting, and Annealing of Copper Surfaces. Phys. Rev. Lett. 1993, 71, 1023-1026. 
(29) Miyake, T.; Oodake, I.; Petek, H. Lateral Thermal Expansion of $\mathrm{Cu}(110)$ Surface Studied with Helium Atom Scattering. Surf. Sci. 1999, 427-28, 39-43.

(30) Ma, S. K. S.; Dewette, F. W.; Alldredge, G. P. Surface Relaxation and Thermal-Expansion for the (001) Face of Alpha-Fe and Cu. Surf. Sci. 1978, 78, 598-624.

(31) Costa, S. D.; Weis, J. E.; Frank, O.; Kalbac, M. Temperature and Face Dependent Copper-Graphene Interactions. Carbon 2015, 93, 793-799.

(32) Frank, O.; Vejpravova, J.; Holy, V.; Kavan, L.; Kalbac, M. Interaction between Graphene and Copper Substrate: The role of Lattice Orientation. Carbon 2014, 68, 440-451.

(33) Wang, Z. J.; Weinberg, G.; Zhang, Q.; Lunkenbein, T.; KleinHoffmann, A.; Kurnatowska, M.; Plodinec, M.; Li, Q.; Chi, L.; Schloegl, R.; Willinger, M. G. Direct Observation of Graphene Growth and Associated Copper Substrate Dynamics by in situ Scanning Electron Microscopy. ACS Nano 2015, 9, 1506-19.

(34) Zhang, Y.; Gao, T.; Gao, Y.; Xie, S.; Ji, Q.; Yan, K.; Peng, H.; Liu, Z. Defect-like Structures of Graphene on Copper Foils for Strain Relief Investigated by High-Resolution Scanning Tunneling Microscopy. ACS Nano 2011, 5, 4014-22.

(35) Xu, K.; Cao, P. G.; Heath, J. R. Scanning Tunneling Microscopy Characterization of the Electrical Properties of Wrinkles in Exfoliated Graphene Monolayers. Nano Lett. 2009, 9, 4446-4451.

(36) Brown, L.; Lochocki, E. B.; Avila, J.; Kim, C. J.; Ogawa, Y.; Havener, R. W.; Kim, D. K.; Monkman, E. J.; Shai, D. E.; Wei, H. F. I.; Levendorf, M. P.; Asensio, M.; Shen, K. M.; Park, J. Polycrystalline Graphene with Single Crystalline Electronic Structure. Nano Lett. 2014, 14, 5706-5711.

(37) Nguyen, V. L.; Shin, B. G.; Duong, D. L.; Kim, S. T.; Perello, D.; Lim, Y. J.; Yuan, Q. H.; Ding, F.; Jeong, H. Y.; Shin, H. S.; Lee, S. M.; Chae, S. H.; Vu, Q. A.; Lee, S. H.; Lee, Y. H. Seamless Stitching of Graphene Domains on Polished Copper (111) Foil. Adv. Mater. 2015, 27, 1376-1382.

(38) Hu, B. S.; Ago, H.; Ito, Y.; Kawahara, K.; Tsuji, M.; Magome, E.; Sumitani, K.; Mizuta, N.; Ikeda, K.; Mizuno, S. Epitaxial Growth of Large-Area Single-Layer Graphene over $\mathrm{Cu}(111) /$ Sapphire by Atmospheric Pressure CVD. Carbon 2012, 50, 57-65.

(39) Miller, D. L.; Keller, M. W.; Shaw, J. M.; Chiaramonti, A. N.; Keller, R. R. Epitaxial (111) Films of $\mathrm{Cu}, \mathrm{Ni}$, and CuxNiy on AlphaAl2O3 (0001) for Graphene Growth by Chemical Vapor Deposition. J. Appl. Phys. 2012, 112, 064317-064326.

(40) Oh, S. H.; Scheu, C.; Wagner, T.; Tchernychova, E.; Ruhle, M. Epitaxy and Bonding of $\mathrm{Cu}$ Films on Oxygen-Terminated AlphaAl2O3(0001) Surfaces. Acta Mater. 2006, 54, 2685-2696.

(41) Nguyen, V. L.; Perello, D. J.; Lee, S.; Nai, C. T.; Shin, B. G.; Kim, J. G.; Park, H. Y.; Jeong, H. Y.; Zhao, J.; Vu, Q. A.; Lee, S. H.; Loh, K. P.; Jeong, S. Y.; Lee, Y. H. Wafer-Scale Single-Crystalline AB-Stacked Bilayer Graphene. Adv. Mater. 2016, 28, 8177-8183.

(42) Miller, D. L.; Keller, M. W.; Shaw, J. M.; Rice, K. P.; Keller, R. R.; Diederichsen, K. M. Giant Secondary Grain Growth in Cu Films on Sapphire. AIP Adv. 2013, 3, 082105-082115.

(43) Yu, V.; Whiteway, E.; Maassen, J.; Hilke, M. Raman Spectroscopy of the Internal Strain of a Graphene Layer Grown on Copper Tuned by Chemical Vapor Deposition. Phys. Rev. B: Condens. Matter Mater. Phys. 2011, 84, 205407-205412.

(44) Mohiuddin, T. M. G.; Lombardo, A.; Nair, R. R.; Bonetti, A.; Savini, G.; Jalil, R.; Bonini, N.; Basko, D. M.; Galiotis, C.; Marzari, N.; Novoselov, K. S.; Geim, A. K.; Ferrari, A. C. Uniaxial Strain in Graphene by Raman Spectroscopy: G peak Splitting, Gruneisen Parameters, and Sample Orientation. Phys. Rev. B: Condens. Matter Mater. Phys. 2009, 79, 205433-205441.

(45) Yan, J.; Zhang, Y. B.; Kim, P.; Pinczuk, A. Electric Field Effect Tuning of Electron-Phonon Coupling in Graphene. Phys. Rev. Lett. 2007, 98, 166802-166806.

(46) Walter, A. L.; Nie, S.; Bostwick, A.; Kim, K. S.; Moreschini, L.; Chang, Y. J.; Innocenti, D.; Horn, K.; McCarty, K. F.; Rotenberg, E. Electronic Structure of Graphene on Single-Crystal Copper Substrates. Phys. Rev. B: Condens. Matter Mater. Phys. 2011, 84, 165443-195450.
(47) Wilson, N. R.; Marsden, A. J.; Saghir, M.; Bromley, C. J.; Schaub, R.; Costantini, G.; White, T. W.; Partridge, C.; Barinov, A.; Dudin, P.; Sanchez, A. M.; Mudd, J. J.; Walker, M.; Bell, G. R. Weak Mismatch Epitaxy and Structural Feedback in Graphene Growth on Copper Foil. Nano Res. 2013, 6, 99-112.

(48) Das, A.; Pisana, S.; Chakraborty, B.; Piscanec, S.; Saha, S. K.; Waghmare, U. V.; Novoselov, K. S.; Krishnamurthy, H. R; Geim, A. K.; Ferrari, A. C.; Sood, A. K. Monitoring Dopants by Raman Scattering in an Electrochemically Top-Gated Graphene Transistor. Nat. Nanotechnol. 2008, 3, 210-215.

(49) Bronsgeest, M. S.; Bendiab, N.; Mathur, S.; Kimouche, A.; Johnson, H. T.; Coraux, J.; Pochet, P. Strain Relaxation in CVD Graphene: Wrinkling with Shear Lag. Nano Lett. 2015, 15, 5098-5104.

(50) Yoon, D.; Son, Y. W.; Cheong, H. Strain-Dependent Splitting of the Double-Resonance Raman Scattering Band in Graphene. Phys. Rev. Lett. 2011, 106, 155502-155506.

(51) Lee, J. E.; Ahn, G.; Shim, J.; Lee, Y. S.; Ryu, S. Optical Separation of Mechanical Strain from Charge Doping in Graphene. Nat. Commun. 2012, 3, 1024

(52) Ding, F.; Ji, H. X.; Chen, Y. H.; Herklotz, A.; Dorr, K.; Mei, Y. F.; Rastelli, A.; Schmidt, O. G. Stretchable Graphene: A Close Look at Fundamental Parameters through Biaxial Straining. Nano Lett. 2010, 10, 3453-3458.

(53) Zabel, J.; Nair, R. R.; Ott, A.; Georgiou, T.; Geim, A. K.; Novoselov, K. S.; Casiraghi, C. Raman Spectroscopy of Graphene and Bilayer under Biaxial Strain: Bubbles and Balloons. Nano Lett. 2012, 12, $617-621$.

(54) Lazzeri, M.; Mauri, F. Nonadiabatic Kohn Anomaly in a Doped Graphene Monolayer. Phys. Rev. Lett. 2006, 97, 198-201.

(55) Pisana, S.; Lazzeri, M.; Casiraghi, C.; Novoselov, K. S.; Geim, A. K.; Ferrari, A. C.; Mauri, F. Breakdown of the Adiabatic BornOppenheimer Approximation in Graphene. Nat. Mater. 2007, 6, 198201

(56) Gao, L.; Guest, J. R.; Guisinger, N. P. Epitaxial Graphene on $\mathrm{Cu}(111)$. Nano Lett. 2010, 10, 3512-3516.

(57) Wei, Y. J.; Wang, B. L.; Wu, J. T.; Yang, R. G.; Dunn, M. L. Bending Rigidity and Gaussian Bending Stiffness of Single-Layered Graphene. Nano Lett. 2013, 13, 26-30.

(58) Pan, Z. H.; Liu, N.; Fu, L.; Liu, Z. F. Wrinkle Engineering: A New Approach to Massive Graphene Nanoribbon Arrays. J. Am. Chem. Soc. 2011, 133, 17578-17581.

(59) Gupta, A. K.; Nisoli, C.; Lammert, P. E.; Crespi, V. H.; Eklund, P. C. Curvature-Induced D-Band Raman Scattering in Folded Graphene. J. Phys.: Condens. Matter 2010, 22, 334205-334211.

(60) Lin, L.; Sun, L. Z.; Zhang, J. C.; Sun, J. Y.; Koh, A. L.; Peng, H. L.; Liu, Z. F. Rapid Growth of Large Single-Crystalline Graphene via Second Passivation and Multistage Carbon Supply. Adv. Mater. 2016 $28,4671-4677$.

(61) Wang, H.; Xu, X. Z.; Li, J. Y.; Lin, L.; Sun, L. Z.; Sun, X.; Zhao, S. L.; Tan, C. W.; Chen, C.; Dang, W. H.; Ren, H. Y.; Zhang, J. C.; Deng, B.; Koh, A. L.; Liao, L.; Kang, N.; Chen, Y. L.; Xu, H. Q.; Ding, F.; Liu, K. H.; et al. Surface Monocrystallization of Copper Foil for Fast Growth of Large Single-Crystal Graphene under Free Molecular Flow. Adv. Mater. 2016, 28, 8968-8974.

(62) Plimpton, S. Fast Parallel Algorithms for Short-Range MolecularDynamics. J. Comput. Phys. 1995, 117, 1-19.

(63) Stuart, S. J.; Tutein, A. B.; Harrison, J. A. A Reactive Potential for Hydrocarbons with Intermolecular Interactions. J. Chem. Phys. 2000, $112,6472-6486$

(64) Foiles, S. M.; Baskes, M. I.; Daw, M. S. Embedded-Atom-Method Functions for the Fcc Metals $\mathrm{Cu}, \mathrm{Ag}, \mathrm{Au}, \mathrm{Ni}, \mathrm{Pd}, \mathrm{Pt}$, and Their Alloys. Phys. Rev. B: Condens. Matter Mater. Phys. 1986, 33, 7983-7991.

(65) Shi, X. H.; Yin, Q. F.; Wei, Y. J. A Theoretical Analysis of the Surface Dependent Binding, Peeling and Folding of Graphene on Single Crystal Copper. Carbon 2012, 50, 3055-3063.

(66) Chen, H.; Chen, S. H. The Peeling Behaviour of a Graphene Sheet on a Nano-Scale Corrugated Surface. J. Phys. D: Appl. Phys. 2013, 46, $435305-435314$ 